\title{
Reproductibilité technique et crise de la culture : Art et politique chez Benjamin et Arendt
}

\section{Par DANIELLE LORIES}

Université catholique de Louvain

Quelque vingt-cinq ans après Walter Benjamin dans son fameux essai sur «L'CEuvre d'art à l'époque de sa reproductibilité technique », Hannah Arendt s'est penchée dans un texte intitulé «La Crise de la culture » sur le même moment critique de l'histoire de l'art et de la culture européenne, qui débouche, selon Benjamin, sur « la liquidation de la valeur traditionnelle de l'héritage culturel »' et, dans les termes d'Arendt, sur la «liquidation générale des valeurs » culturelles, qu'elle situe dans les années 1920-1930 en Allemagne, 1940-1950 en France ${ }^{2}$.

Tous deux dans leurs analyses lient cette crise au phénomène de massification de la société et font remonter l'examen de la question au XIX siècle, pointant l'un la naissance de la photographie, qui « contenait virtuellement le cinéma $»^{3}$, l'autre le kitsch, qui reflétait « la séparation des arts et de la réalité $»^{4}$, comme phénomènes particulièrement symptomatiques du déclenchement de cette crise culturelle, et donc aussi de son enjeu proprement politique.

La conception du politique qui commande la lecture de ladite crise ou liquidation est à l'évidence très différente dans l'un et l'autre cas, mais une

${ }^{1}$ Walter Benjamin, «L'CEuvre d'art à l'époque de sa reproductibilité technique » (1939), trad. fr. M. de Gandillac revue par R. Rochlitz, dans Id., Euvres III, trad. fr. M. de Gandillac, R. Rochlitz, P. Rusch, Paris, Éditions Gallimard, 2000, p. 276.

${ }^{2}$ Hannah Arendt, « La Crise de la culture », trad. fr. B. Cassin, dans Id., La Crise de la culture. Huit exercices de pensée politique, trad. fr. collective, Paris, Éditions Gallimard, 1972, p. 262.

${ }^{3}$ Walter Benjamin, «L'Euvre d'art à l'époque de sa reproductibilité technique », art. cit., p. 272.

${ }^{4}$ Hannah Arendt, La Crise de la culture, op. cit., p. 261. 
confrontation des deux argumentaires peut jeter un éclairage intéressant aujourd'hui sur notre rapport à certaines de ces valeurs « liquidées » de la tradition esthétique. La confrontation ne saurait être menée de manière exhaustive ici, je centrerai donc mon propos sur deux notions dont l'importance est indéniable dans les deux cas: le caractère public de l'œuvre et l'autonomie de la sphère artistique ${ }^{1}$.

Pour l'essentiel, et faute d'espace, la présente étude s'en tiendra aux deux textes mentionnés, même si l'on pourrait défendre l'idée que la notion si fameuse d'aura chez Benjamin mériterait d'être suivie dans son évolution et dans la réévaluation de la perte de l'aura qu'il est possible de lire dans des textes ultérieurs ${ }^{2}$, et même si, chez Arendt, il est impossible de ne pas associer l'analyse de « La Crise de la culture » aux thèses de la Condition de l'homme moderne dont la parution précède de peu l'élaboration de la première version de l'article paru dans Daedalus en $1960^{3}$.

Dans l'avant-propos où il se réclame de Marx, Benjamin annonce la « valeur polémique» de ses "thèses sur les tendances évolutives de l'art dans les conditions présentes de la production » et la mise à l'écart par ce qu'il nomme sa «politique de l'art» des « concepts traditionnels - création et génie, valeur d'éternité et mystère $»^{4}$.

Si l'œuvre d'art fut de tout temps reproductible et reproduite, copiée, l'apparition de la photographie, présentée comme précurseur du cinéma dont la portée proprement politique fait l'objet de toute la seconde moitié de l'essai, cette apparition au XIX ${ }^{\mathrm{e}}$ siècle est totalement novatrice parce que ce sont les tâches proprement artistiques, celles dévolues traditionnellement à la main, qui désormais sont confiées « à l'œil rivé à l'objectif » ${ }^{5}$. Avec la reproduction en masse par la photographie, l'œuvre traditionnelle perd son carac-

${ }^{1}$ On pourrait mener la comparaison de manière intéressante sur d'autres notions, ainsi du concept de génie.

${ }^{2}$ Cf. Rainer Rochlitz, Le Désenchantement de l'art. La philosophie de Walter Benjamin, Paris, Éditions Gallimard, 1992, en particulier II.

${ }^{3}$ L'analyse se centrera sur la première moitié des deux textes considérés, sauf incursions nécessaires pour suivre une thématique. En effet, à partir des sections VII et VIII Benjamin se consacre presque exclusivement à l'analyse du cinéma, analyse qui a peu d'écho, comme telle, chez Arendt. Le texte d'Arendt est quant à lui expressément divisé en deux sections dont la seconde traite plus particulièrement du concept de culture, lequel n'est pas comme tel traité par Benjamin, de sorte que les points de comparaison demeurent plus rares ou relativement accessoires.

${ }^{4}$ Walter Benjamin, «L'CEuvre d'art à l'époque de sa reproductibilité technique », art. cit., p. 270-71.

${ }^{5}$ Ibid., p. 272. 
tère d'objet unique, son hic et nunc, sa valeur d'authenticité et son autorité liées à son origine.

À l'unicité et à la durée traditionnelle de l'œuvre originale, et donc à son aura, se substituent ainsi la répétabilité et la fugacité de la reproduction. Ce constat, Arendt le formulera à son tour : la durée et l'unicité traditionnelles cèdent le pas à la répétition et au caractère éphémère.

Sur la question de la publicité de l'œuvre, c'est le passage de la valeur cultuelle à la valeur d'exposition qui doit retenir l'attention dans le texte de Benjamin.

En corrélation avec son examen de l'évolution des modes de production et de reproduction de l'œuvre, son essai considère les modifications de la « façon de percevoir» des communautés humaines ${ }^{1}$. À cet égard, Benjamin souligne deux pôles dans la réception des œuvres, selon que l'accent porte sur leur valeur cultuelle ou sur leur valeur d'exposition ${ }^{2}$. Il insiste sur ceci que «la production artistique commence par des images qui servent au culte » et qu'à ce point de vue "l'existence même de ces images " importe plus que « le fait qu'elles soient vues » - l'image cultuelle a une dimension essentiellement spirituelle et peut aussi bien être "gardée au secret ${ }^{3}$; et c'est à mesure que les pratiques artistiques «s'émancipent du rituel » que l'exposition (qui a toujours existé, et a même toujours dominé en ce qui concerne les œuvres d'architecture par exemple) s'impose toujours davantage ${ }^{4}$.

Si la reproduction met à mal l'unicité, c'est tout le rapport à la tradition qui est mis en cause, car «l'unicité de l'œuvre d'art et son intégration à la tradition ne sont qu'une seule et même chose $»^{5}$.

Or l'œuvre d'art entre dans la tradition par le culte :

On sait que les plus anciennes œuvres d'art naquirent au service d'un rituel, magique d'abord, puis religieux. Or, c'est un fait de la plus haute importance que ce mode d'existence de l'œuvre d'art, lié à l'aura, ne se dissocie jamais absolument de sa fonction rituelle. En d'autres termes, la valeur unique de

\footnotetext{
${ }^{1}$ Ibid., p. 277.

${ }^{2}$ Ibid., p. 282.

${ }^{3}$ Ibid., p. 283.

${ }^{4}$ Ibid., p. 284.

${ }^{5}$ Ibid., p. 279.
} 
l'œuvre d'art « authentique » se fonde sur ce rituel qui fut sa valeur d'usage originelle et première ${ }^{1}$.

Ce fondement dans le rituel, on le reconnaît encore " comme un rituel sécularisé, jusque dans les formes les plus profanes du culte de la beauté $»^{2}$.

Datant de la Renaissance, ce culte profane qui perdure jusqu'au XIX ${ }^{\mathrm{e}}$ siècle révèle alors particulièrement ce fondement parce qu'il est ébranlé par les techniques nouvelles de reproduction; il le révèle en produisant, dans un mouvement de défense, la doctrine de l'art pour l'art, véritable «théologie négative » refusant à l'art « toute fonction sociale » et « toute évocation d'un sujet concret» ${ }^{3}$ : pour la première fois au XIX ${ }^{\mathrm{e}}$ siècle «l'œuvre d'art s'émancipe de l'existence parasitaire qui lui était impartie dans le cadre du rituel ${ }^{4}$ — illusoire est cette ultime revendication d'autonomie aux yeux de Benjamin.

Et quand le "critère d'authenticité n'est plus applicable à la production artistique, toute la fonction de l'art se trouve bouleversée. Au lieu de reposer sur le rituel, elle se fonde désormais sur une autre pratique: la politique $»^{5}$. Et Benjamin d'ajouter que comme «la prépondérance absolue de la valeur cultuelle » faisait à l'âge préhistorique de l'œuvre " un instrument magique », dont le " caractère artistique » ne fut admis que plus tard, de même " aujourd'hui la prépondérance absolue de sa valeur d'exposition lui assigne des fonctions tout à fait neuves » telles que sa « fonction artistique » pourrait bien s'avérer à l'avenir « accessoire $»^{6}$.

Cette fonction que Benjamin appelle «artistique», dont nous sommes encore conscients, selon lui, et qui pourrait disparaître bientôt, est éclairée par une note renvoyant à Brecht qui écrivait que quand l'œuvre d'art devient marchandise, c'est la notion d'œuvre d'art qu'on ne peut plus lui appliquer ${ }^{7}$. Il semble donc que la fonction artistique telle que Benjamin l'entend - celle qui selon cette appellation semblerait définir l'art en tant qu'art -, tout en évoquant une production du beau (le «Bel Art» des modernes), renvoie à toutes les valeurs « traditionnelles » évoquées : parlant des premières photographies où se manifeste encore partiellement la valeur cultuelle, comme culte du souvenir des êtres chers dans les portraits photographiques, Benja-

${ }^{1}$ Ibid., p. 280.

${ }^{2}$ Idem.

${ }^{3}$ Ibid., p. 281 .

${ }^{4}$ Idem.

${ }^{5}$ Ibid., p. 282.

${ }^{6}$ Ibid., p. 284-285.

${ }^{7}$ Ibid., p. 285, note 1 . 
min y voit le lieu où « l'aura fait signe une dernière fois », ce qui donne à ces clichés « leur incomparable beauté $»^{1}$.

Quant aux fonctions neuves de l'œuvre, les analyses de la photographie et du cinéma doivent les révéler dans la mesure même où la valeur d'exposition y triomphe, c'est-à-dire aussi le caractère résolument public.

Ce qui apparaît clairement ici, c'est que toute la portée de l'œuvre d'art, qu'elle soit traditionnelle ou nouvelle, toute sa signification réside dans sa fonction, s'inscrit dans un registre qui est celui de l'instrumentalité, des relations de moyens à fin. Instrument du rite et du culte à l'origine, l'œuvre a une valeur d'usage, qui au fil du temps se double d'une valeur d'échange, et d'une valeur marchande, d'autant plus aisément que le culte s'est progressivement sécularisé, qu'il est devenu profane, que la valeur cultuelle de l'image a cédé la place à un fétichisme de l'œuvre originale et authentique, c'est-à-dire dont la " traçabilité », dirait-on aujourd'hui, jusqu'à tel individu artiste est assurée. Le culte du génie artiste remplaçant pour ainsi dire celui de la divinité tout en dégénérant en une marchandisation toujours accrue qui s'achève dans l'usage capitaliste du cinéma, c'est-à-dire dans le culte hollywoodien de la vedette: "Le culte de la vedette, que favorise le capitalisme des producteurs de films, conserve cette magie de la personnalité qui, depuis longtemps déjà, se réduit aux charmes faisandés de son caractère mercantile $»^{2}$.

Dans le contraste en jeu dans le présent propos entre son analyse et celle d'Arendt, ce qui est frappant, c'est d'une part que, selon Benjamin, il ne semble pas que le caractère public de l'œuvre d'art lui soit essentiel, en tout cas dans son sens traditionnel, puisque ce sens reste tributaire de la valeur d'usage cultuel ; c'est, d'autre part, que ce caractère public devient crucial quand il s'agit de redéfinir les fonctions neuves, politiques, de l'œuvre transfigurée par la reproductibilité technique. Et, enfin, c'est que tant quant à l'œuvre traditionnelle que quant à l'œuvre nouvelle, Benjamin ne raisonne qu'en terme seulement de fonctionnalités de l'œuvre : l'œuvre est et n'est jamais qu'un instrument. Un instrument du culte, qui se sécularise, se faisande, se mercantilise ; puis, l'instrument technique d'une action politique et révolutionnaire que l'auteur appelle de ses vœux. L'importance soulignée

\footnotetext{
${ }^{1}$ Idem. On remarquera dès à présent que dans le culte profane de la beauté, progressivement, «à l'unicité de ce qui apparaît dans l'image cultuelle » s'est substituée "l'unicité empirique du créateur et de son activité créatrice » (ibid., p. 280, note 2); qu'ainsi la prosaïque «garantie d'origine» tend à s'imposer comme une sorte de fétichisme de la signature, ce qui renvoie à la notion moderne de génie.

${ }^{2}$ Ibid., p. 295.
} 
du caractère public de l'œuvre n'est que la conséquence d'un changement fonctionnel. Et la fonction proprement «artistique » ne semble être qu'un intermédiaire historique, moderne, entre la fonction religieuse et le naufrage de l'ensemble des valeurs dites traditionnelles de l'œuvre, toutes liées à cet intermède qui s'achève avec le mouvement de l'art pour l'art, au moment où les techniques de reproduction ouvrent les portes aux fonctions politiques nouvelles de l'art ${ }^{1}$.

Sur tout ceci, Arendt est bien loin d'entériner l'analyse, tout en reconnaissant une signification politique et publique considérable, mais bien plus essentielle, à l'œuvre d'art.

Dans la Condition de l'homme moderne, ouvrage qui donne l'orientation générale de l'analyse de "La Crise de la culture», elle écrit, sur les valeurs d'usage et d'échange de l'œuvre et sa marchandisation :

Les objets qui donnent à l'artifice humain la stabilité qui lui permet d'être la patrie des mortels sont en particulier ceux qui n'ont aucune utilité, et qui parce qu'ils sont uniques ne sont pas échangeables et défient par conséquent l'égalisation au moyen d'un dénominateur commun comme l'argent ${ }^{2}$.

Ensuite, sur l'origine cultuelle, magique ou religieuse de l'œuvre :

Que l'œuvre d'art ait toujours été inutile, ou qu'elle ait autrefois servi aux prétendus besoins religieux comme les objets d'usage ordinaire servent aux besoins ordinaires, c'est une question hors de propos ici. Même si l'origine historique de l'art était d'un caractère exclusivement religieux ou mythologique, le fait est que l'art a glorieusement résisté à sa séparation d'avec la religion, la magie, et le mythe ${ }^{3}$.

\footnotetext{
${ }^{1}$ Le mouvement reproduit en un sens le mouvement hégélien qui mène à la mort de l'art ; mais c'est aussi ici le mouvement marxien par lequel on devrait aboutir à une société sans classe dans laquelle tout un chacun est artiste à ses heures, ce qui revient de toute façon à la mort de l'art. Le devenir «expert» du spectateur du cinéma (ibid., p. 295 et p. 313), et la légitimité de la revendication par tout un chacun de son droit à l'image (ibid., p. 296) et à la parole d'expert en sa partie, reconnus par Benjamin, vont en ce sens. Et rien de cela ne sort du registre de l'instrumentalité : l'expert est technicien, comme auteur ou comme spectateur, il évalue des moyens eu égard à une fin.

${ }^{2}$ Hannah Arendt, Condition de l'homme moderne (1961), trad. fr. G. Fradier, Paris, Éditions Calmann-Lévy, 1983, p. 187.

${ }^{3}$ Ibid., p. 187-188.
} 
Qui plus est, loin d'être définie tout entière par sa fonction cultuelle traditionnelle ou par sa fonction politique nouvelle, l'œuvre d'art ne prend sens dans la sphère politique que de transcender le registre des besoins que ce soit des individus ou de la société, comme celui des fonctions et de l'utilité : «Leur beauté transcende tout besoin, et les fait durer à travers les siècles. Mais si [elle] transcende besoins et fonctions, jamais elle ne transcende le monde, même s'il arrive que l'œuvre ait un contenu religieux ». Il faut au contraire dire que «tout art est séculier » et que l'art religieux « réifie et transforme en présence "objective", tangible, mondaine, ce qui n'existait auparavant qu'en dehors du monde $\|^{1}$ : peu importe où la religion ou la psychologie peuvent situer cet «en dehors du monde », ce qui importe ici c'est que l'art, en tant qu'art, lui donne une présence au monde dans l'apparaître des formes de l'œuvre, dans ce qu'elles ont d'inutile.

Menée du point de vue politique, elle aussi, l'analyse d'Arendt vise à dégager une essence, en-deçà des fonctions variant dans l'histoire.

Non pas évidemment qu'Arendt annihile l'évolution historique, ni la crise $\mathrm{du} \mathrm{XIX}^{\mathrm{e}}$ siècle, mais elle interprète celle-ci au regard de ce qu'elle considère comme les traits essentiels de l'œuvre envisagée dans sa signification proprement politique, c'est-à-dire d'abord publique. Ce n'est pas non plus que la production en nombre liée à la massification de la société ne possède pas à ses yeux de portée qualitative sur ce qui est produit, bien au contraire. Mais elle analyse les faits de cette phase historique à la lumière des distinctions essentielles qui concernent les activités humaines. Sa perspective est politique, mais au sens où ce mot fait référence à l'être-ensemble des hommes, aux conditions de ce vivre-ensemble. En ce sens, l'art possède d'emblée un aspect politique, il implique ou présuppose cet être-ensemble des hommes : on n'est pas un producteur d'œuvres d'art pour et par soi seul ; l'œuvre n'est œuvre que pour un public; l'art comme le beau renvoient à l'essentielle sociabilité des hommes, comme l'avait vu Kant, et même aux conditions de possibilité de leur « être-ensemble».

On sait que la vita activa rassemble trois types essentiellement différents d'activités chez Arendt. C'est la condition de l'homme d'être d'abord animal laborans, c'est-à-dire de devoir par son travail ou labeur assurer sa propre subsistance, l'ensemble des nécessités vitales. Il est aussi homo faber, car il produit «la pure variété infinie des choses dont la somme totale constitue

${ }^{1}$ Hannah Arendt, La Crise de la culture, op. cit., p. 267. 
l'artifice humain, le monde dans lequel nous vivons $»^{1}$. Ce monde d'artifice durable qui «stabilise la vie humaine $»^{2}$ est pour la pluralité des hommes : c'est à eux seuls qu'il faut un habitat susceptible de délimiter un espace public propre à la révélation de qui ils sont par l'action et la parole et c'est par la pluralité que ce monde a une réalité « objective », parce qu'il leur est commun ${ }^{3}$.

C'est à travers la compréhension de l'action que ce monde - cet environnement artificiel qui protège les hommes du flux de la nature et de la vie $^{4}$ - peut se montrer comme le lieu objectif, indépendant de chacun, de chaque naissance d'êtres humains chaque fois uniques, qui vont insérer « dans la société de [leur] propre espèce » leur « unicité » propre par l'action et la parole ${ }^{5}$. C'est dans ces relations que surgit la dimension propre du sens, par-delà l'utilité et les nécessités biologiques. Le monde constitué par les œuvres de l'homo faber n'a de sens que par et pour l'homme d'action et de parole.

Si l'animal laborans a besoin de l'homo faber pour faciliter son travail et soulager sa peine, les hommes au pluriel ont besoin de lui pour édifier une patrie sur terre, qui soit un monde humain au sens propre; quant aux hommes d'action,

ils ont besoin de l'homo faber en sa capacité la plus élevée : ils ont besoin de l'artiste, du poète et de l'historiographe, du bâtisseur de monuments ou de l'écrivain, car sans eux le seul produit de leur activité, l'histoire qu'ils jouent et qu'ils racontent, ne survivrait pas un instant ${ }^{6}$.

Dans l'ouvrage de 1958, l'analyse du mouvement historique montre que la modernité met déjà en péril la reconnaissance de la spécificité du domaine public par opposition au privé ${ }^{7}$, en même temps que la spécificité de l'action et de la parole par rapport au registre de la fabrication : la mentalité moderne considère que savoir, c'est pouvoir, c'est-à-dire faire, fabriquer, et le politique est saisi - la modernité achevant ainsi un glissement déjà sensible

${ }^{1}$ Hannah Arendt, «Travail, œuvre, action», trad. fr. D. Lories, Études phénoménologiques, $\mathrm{I}, \mathrm{n}^{\circ} 2$, p. 12.

${ }^{2}$ Hannah Arendt, Condition de l'homme moderne, op. cit., p. 154.

${ }^{3}$ «Le seul caractère du monde qui permette d'en mesurer la réalité, écrit Arendt, c'est qu'il nous est commun à tous » (ibid., p. 234).

${ }^{4}$ Hannah Arendt, « Travail, œuvre, action », art. cit., p. 14.

${ }^{5}$ Ibid., p. 21.

${ }^{6}$ Hannah Arendt, Condition de l'homme moderne, op. cit., p. 195.

${ }^{7}$ Ce phénomène s'est encore accru ensuite. 
chez Platon - sur le modèle de la fabrication, c'est-à-dire de la maitrise où l'auteur est maître de ses matériaux, de ses outils, de son œuvre, alors que l'action, comme interaction, est imprévisible dans ses conséquences, et irréversible, c'est-à-dire que l'acteur n'est nullement en position de maitrise par rapport à ce qu'il fait, ce qui devrait interdire de tenter de comprendre l'action à partir du modèle de l'œuvrer. Des modernes à notre monde contemporain, le glissement s'effectue ensuite de cette prééminence de l'homo faber vers celle de l'animal laborans : c'est l'homme travailleur et consommateur qui l'emporte toujours davantage. La crise de la culture prend place dans ce mouvement d'ensemble et son analyse s'effectue dans ces catégories.

Arendt montre d'abord que l'antagonisme entre culture et société n'a pas attendu l'apparition de la société de masse, mais qu'il s'agit plutôt d'un phénomène propre à l'âge moderne, lié à l'avènement de la société ellemême. «Tout le mouvement de l'art moderne, écrit-elle, commença par une rébellion véhémente de l'artiste contre la société en tant que telle (et non contre une société de masse encore inconnue) » ${ }^{1}$. L'accusation de l'artiste envers la société - qu'Arendt envisage ici en tant qu'il est « le producteur authentique des objets que chaque civilisation laisse derrière elle comme la quintessence et le témoignage durable de l'esprit qui l'anime $»^{2}$ — fut d'abord celle de philistinisme - cet « état d'esprit qui juge de tout en termes d'utilité immédiate et de "valeurs matérielles", et n'a donc pas d'yeux pour des objets et des occupations aussi inutiles que ceux relevant de la nature et de l'art $»^{3}$.

Mais cette société ne resta pas simplement "inculte et inintéressée » par les œuvres de l'art, elle se mit à les faire servir à ses visées propres : le bourgeois s'en empara comme d'un moyen d'ascension sociale, visant à atteindre une reconnaissance supérieure liée à un raffinement dans l'éducation et à la perfection de soi. Par ces moyens il s'agissait de «[sortir] des basses régions où l'on supposa le réel situé, jusqu'aux régions élevées de l'irréel, où la beauté et l'esprit étaient, supposait-on, chez eux ». C'est contre cet usage de l'art et de la culture que les artistes se révoltèrent, refusant d'être « expulsés de la réalité dans une sphère de conversation raffinée où ce qu'ils font perd toute signification $»^{4}$, leur sens étant d'édifier un monde humain durable, partagé et transmissible de génération en génération. La culture forme une monde objectif, fait de choses tangibles et les normes

\footnotetext{
${ }^{1}$ Hannah Arendt, La Crise de la culture, op. cit., p. 254.

2 Ibid., p. 257.

${ }^{3}$ Ibid., p. 258.

${ }^{4}$ Ibid., p. 259.
} 
sociales d'éducation raffinée ne s'y adaptent nullement: le seul critère qui vaut à ce sujet est la permanence, la durée, voire une sorte d'immortalité au point que : "Seul ce qui dure à travers les siècles peut finalement revendiquer d'être un objet culturel $»^{1}$.

On voit bien que, dans la perspective arendtienne, nous ne sommes pas dans le schéma «traditionnel » de l'esthétique moderne où l'essentiel pour l'œuvre est l'effet produit sur nos subjectivités individuelles. Cette dimension n'est pas négligée mais apparaît comme subordonnée à cette permanence foncière des objets mondains que sont les objets culturels et par excellence les œuvres d'art, puisque c'est grâce à cette durée qu'ils possèdent «leur plus importante et leur plus fondamentale qualité : ravir et émouvoir le lecteur ou le spectateur par-delà les siècles $»^{2}$.

La « désintégration de la culture ${ }^{3}$ entamée par la société philistine éduquée sera achevée au $\mathrm{XX}^{\mathrm{e}}$ siècle par l'animal laborans. Alors « le fil de la tradition »se brise ${ }^{4}$. La société philistine, où l'avait emporté la mentalité utilitaire de l'homo faber, usant et abusant des choses culturelles comme de moyens pour ses fins propres, a fait place à la société, massifiée, de consommation. Ce que le philistin cultivé utilisait, les produits culturels, l'individu de la masse le consommera. Quand le premier, autrement dit, ramenait l'œuvre d'art au registre banausique de l'œuvrer ordinaire, de la fabrication, des moyens et des fins, registre dont elle est issue mais qu'elle transcende précisément par son rapport à la polis, à l'espace public, à l'action et à la parole qui s'y jouent et s'y échangent, le second la ravale au rang des nécessités vitales et du labeur chargé de les satisfaire, l'introduit dans le cycle naturel du métabolisme ${ }^{5}$, auquel il a toujours été de son essence d'échapper, de par sa durée. De marchandise et objet utilitaire, les produits culturels deviennent biens de consommation satisfaisant le besoin naturel de distraction.

Le danger de la société de masse et de ladite «culture de masse» ne réside bien sûr pas dans le fait que l'ensemble de la population aurait accès à la culture et à l'art, il réside dans l'application aux objets culturels des critères de «la fraîcheur et (de) la nouveauté ${ }^{6}$ qui ne valent que dans

\footnotetext{
${ }^{1}$ Ibid., p. 260.

${ }^{2}$ Idem.

${ }^{3}$ Ibid., p. 261.

${ }^{4}$ Ibid., p. 262.

${ }^{5}$ Les œuvres sont désormais intégrées dans l'ordre biologique du «métabolisme de l'homme avec la nature » (ibid., p. 263, citant Marx).

${ }^{6}$ Ibid., p. 264.
} 
l'ordre de la consommation et de la satisfaction des besoins vitaux. Plus profondément, le danger est dans les « appétits gargantuesques » de loisirs auxquels doit faire face l'industrie qui porte ce nom. Le besoin de distraction est légitime, mais infini, puisque les produits sont destinés à disparaître dans la consommation, il est dès lors problématique de les satisfaire. La menace réside en ceci que l'industrie des loisirs « pille le domaine entier de la culture passée et présente, dans l'espoir de trouver un matériau approprié $»{ }^{1}$. L'objet culturel ou d'art est transformé en matière première d'un produit de consommation-loisir et pour le rendre consommable, digeste, il faut le modifier : le réécrire, le condenser, l'abréger, l'illustrer, etc. : « La culture de masse apparaît quand la société de masse se saisit des objets culturels [...] son danger est que le processus vital de la société [...] consommera littéralement les objets culturels, les engloutira et les détruira $»^{2}$.

Chez les deux auteurs, il s'agit de déceler dans la liquidation des valeurs culturelles un impact du quantitatif sur le qualitatif ${ }^{3}$. Cependant Benjamin veut voir dans l'aspect «destructeur» du cinéma «son aspect cathartique ${ }^{4}$, donc positif, à l'égard de ces valeurs, et voit une invitation à cette "vaste liquidation ${ }^{5}$ dans l'enthousiasme d'Abel Gance : "Shakespeare, Rembrandt, Beethoven feront du cinéma ${ }^{6}$. Arendt en revanche y repère cette destruction de la culture et des œuvres par la consommation de la masse. Ce sont donc la subsistance ou la disparition de la culture et de l'art qui sont en jeu car « la culture concerne les objets et est un phénomène du monde », elle meurt si elle est absorbée par « le loisir [qui] concerne les gens et est un phénomène de la vie $»^{7}$. Plus qu'un simple «milieu de vie», la culture offre un monde d'objets doués d'une durabilité intrinsèque parce qu'ils transcendent le circuit des besoins, et celui des fonctions. L'enjeu est foncièrement politique puisque art et culture ont un rôle spécifique par rapport à la sphère publique du politique.

${ }^{1}$ Ibid., p. 265.

${ }^{2}$ Ibid., p. 265-66. Ou encore ibid., p. 266 : «La culture se trouve menacée quand tous les objets et choses du monde, produits par le présent ou par le passé, sont traités comme de pures fonctions du processus vital de la société, comme s'ils n'étaient là que pour satisfaire quelque besoin ».

${ }^{3}$ Walter Benjamin, «L'CEuvre d'art à l'époque de sa reproductibilité technique », art. cit., p. 310 .

${ }^{4}$ Ibid., p. 276.

${ }^{5}$ Ibid., p. 277.

${ }^{6}$ Ibid., p. 276-77.

${ }^{7}$ Hannah Arendt, La Crise de la culture, op. cit., p. 266. 
Si Arendt voit moins de danger dans les techniques artistiques nouvelles au point de vue de l'œuvre au sens strict — il n'y a pas de raison que les œuvres traditionnelles en souffrent, comme l'écrit Benjamin: leur existence même n'est pas remise en cause ${ }^{1}$ - , le danger vient de ce que ces techniques se mettent au service non de l'art - il n'y a pas de raison non plus de refuser le titre d'art au cinéma ou à une autre technique neuve mais des biens de consommation qui puisent dans l'héritage culturel comme matière.

Pour Arendt, la production d'œuvres d'art ne prend un sens spécifique, dans l'ensemble de l'agir humain, que de contribuer à procurer un monde, qui n'est que par sa durée par delà la vie d'un individu, de transmettre dans ce monde de génération en génération les histoires, les actions des hommes qui disent le sens de l'inter-esse. Ce sens est public, pour et par la pluralité des hommes. L'œuvre réifie ses histoires et permet leur transmission par-delà les siècles. La publicité de l'œuvre est essentielle à son sens dans la vita activa, tant dans l'espace que dans le temps. Le devenir «fugace », l'assimilation dans une consommation sont contraires au sens de l'œuvre et la détruisent en tant qu'art ou qu'objet de culture ; bien loin de lui permettre d'accéder à une fonction politique, ce devenir est destructeur d'un monde commun humain au profit d'une société de consommation où sont de plus en plus brouillées, voire abolies, les limites du privé et du public.

C'est dire que l'œuvre d'art, dans la liquidation des valeurs, bien loin de gagner une "fonction politique " en gagnant en caractère public, est en train de perdre sa réalité de chose de la sphère publique, du-monde, et dès lors de perdre sa capacité à procurer l'habitat durable que requiert l'action politique : elle est en train d'intégrer la sphère en principe privée de la consommation, de la satisfaction des besoins ${ }^{2}$.

Au regard d'une analyse comme celle d'Arendt, celle de Benjamin demeure piégée dans une vision fabricatrice, banausique, à laquelle échappent le vrai sens du politique ainsi que le sens que par rapport à celui-ci prend l'œuvre d'art. Ce piège, on le repère dans l'insistance que met Benjamin sur la

\footnotetext{
${ }^{1}$ Walter Benjamin, «L'CEuvre d'art à l'époque de sa reproductibilité technique », art. cit., p. 275.

${ }^{2}$ Le « social » relève de cette confusion du public et du privé dans la société de marché et de consommation.
} 
fonctionnalité de l'œuvre comme encore dans l'expertise qu'il voit à l'œuvre dans une salle de cinéma.

Selon Arendt, en revanche, la spécificité de l'œuvre d'art par rapport aux autres produits de l'homo faber, c'est que la beauté de l'œuvre ne satisfait pas de besoin, ni n'est utile. L'enjeu de l'œuvre d'art est donc l'existence d'un monde proprement humain, rien de moins. En outre, cette beauté (et la distance avec Benjamin se marque encore) ne transcende pas le monde : elle appartient à des réalités tangibles du monde, parmi les plus durables de toutes et donc les plus mondaines ${ }^{1}$. Pour admirer cet apparaître, il nous faut, selon l'expression kantienne, faire preuve de "désintéressement $»^{2}$, c'est-à-dire mettre à distance les considérations utilitaires et être libéré des nécessités vitales, de manière à "être libres pour le monde", comme dit $\mathrm{Arendt}^{3}$, et capables de juger sur l'apparaître seul des choses.

Loin d'être en rupture avec la tradition, chez Arendt, le sens politique parce que public de l'œuvre d'art, celle-ci le tient de ce que sa beauté, sa forme, son apparaître dans le monde n'a pas à strictement parler de fonction : c'est ainsi qu'elle contribue à donner un monde au sens strict, c'est-à-dire aussi une culture.

Supérieures à toutes les choses du monde par leur durée, les œuvres d'art font exception car elles sont maintenues à l'écart des procès de consommation et d'utilisation, et c'est cette mise à distance qui est constitutive de ce que veut dire le mot culture : "C'est seulement quand elle est accomplie que la culture, au sens spécifique du terme, vient à l'être $»^{4}$. Il y a culture si la subsistance des objets du-monde par-delà les générations est assurée. Sans cet habitat qu'est le monde au sens propre ${ }^{5}$, il n'y a pas de culture. Sans les œuvres d'art comme objets échappant expressément à ces procès vital et utilitaire/fonctionnel, il n'y a pas de monde.

Loin de tenir à une origine mystérieuse dans le culte et à une existence «parasitaire », d'instrument, le sens de l'œuvre d'art tient à son apparaître public, dans un monde partagé, et à sa durée dans ce monde. Aux yeux d'Arendt, le devenir éphémère ou fugace de l'œuvre est en ce sens sa néga-

\footnotetext{
${ }^{1}$ Hannah Arendt, La Crise de la culture, op. cit., p. 268.

${ }^{2}$ Cf. ibid., p. 269.

${ }^{3}$ Ibid., p. 270.

${ }^{4}$ Ibid., p. 268.

${ }^{5} \mathrm{C}$ 'est-à-dire un monde où « la totalité des objets fabriqués est organisée au point de résister au procès de consommation nécessaire à la vie des gens qui y demeurent, et ainsi, de leur survivre » (ibid., p. 269).
} 
tion même : ce n'est plus d'œuvre qu'il s'agit, ni de culture, c'est de consommation et de loisirs, de processus métabolique.

On voit comment la différence de sens et d'appréciation du caractère public de l'œuvre renvoie à une différence du rapport au beau: aura mystérieuse, pointant vers un «ailleurs», un « lointain », une origine cultuelle et rituelle, avec ce que cela comporte de nécessairement inaccessible au savoir, à la raison, d'un côté ; simple éclat des formes libres de toute fonction, de l'apparaître pour l'apparaître, du se-donner-à-voir à la pluralité pour la pluralité, de l'autre. Au lointain qui garde quelque chose de mystique s'oppose un apparaître partagé, parmi nous, séculier. Quant à la proximité de la reproduction, qui s'oppose à l'éloignement de l'œuvre unique traditionnelle, cette proximité n'est rien aux yeux d'Arendt que la proximité «biologique » du bien de consommation, à mille lieues de l'indépendance ou de l'objectivité de l'œuvre par rapport aux individus : la reproduction, bien loin d'avoir une portée «politique» positive, relève d'une privatisation consommatrice de l'œuvre, alors qu'elle n'est œuvre que dans la sphère publique.

Si les mouvements d'ensemble des deux analyses sont fort éloignés, on retrouve néanmoins dans la description du spectateur du cinéma capitaliste par Benjamin des traits qui sont ceux de l'animal laborans d'Arendt.

La question de l'autonomie de la sphère des œuvres d'art a été préparée par l'aperçu qui précède quant à la publicité de l'œuvre, beaucoup d'éléments pertinents à cet égard ont déjà été rassemblés.

Chez Benjamin, on peut lire un pur et simple déni de l'autonomie d'une sphère artistique puisque toute son interprétation du sens de l'œuvre d'art, traditionnelle ou nouvelle, s'exprime en termes d'usage et de fonction. Usage cultuel, usage politique. L'« autonomie» prétendue de la sphère artistique n'est rien qu'une revendication concomitante à la sécularisation du culte, qui demeure néanmoins culte, puisque la doctrine de «l'art pour l'art» est qualifiée de théologie négative ${ }^{1}$. De la fonction rituelle à la fonction politique révolutionnaire, l'œuvre a une existence "parasitaire ». Même au moment où la fonction "artistique » semble l'emporter, cette fonction est celle d'un objet du culte de la beauté, objet d'usage, d'échange, remplissant une fonction de marchandise en même temps que, dans les mains du

${ }^{1}$ Walter Benjamin, «L'Euvre d'art à l'époque de sa reproductibilité technique », art. cit., p. 281. 
collectionneur, de fétiche. Benjamin l'indique du reste : «Une fois que l'art avait été affranchi de ses bases cultuelles par la reproductibilité technique, il perdait à jamais tout semblant d'autonomie ${ }^{1}$ : ce qui est perdu n'est qu'un semblant. Et s'il s'agit d'introduire dans la théorie de l'art de nouveaux concepts "utilisables pour formuler des exigences révolutionnaires », c'est pour remplacer les concepts traditionnels, accusés de se montrer utilisables «pour les buts du fascisme $»^{2}$. Il s'agit moins de faire échapper l'art à l'instrumentalité, donc à la subordination, que de préconiser un usage politique au détriment d'un autre usage politique, fasciste, fondé sur la traditionnelle valeur cultuelle ${ }^{3}$.

Chez Arendt en revanche, le mouvement de «l'art pour l'art» peut apparaître comme une résistance du monde artistique, mais il s'agit cette fois d'une résistance à l'utilisation de l'art à des fins qui lui sont étrangères : l'usage qu'en font les philistins «cultivés » qui instrumentalisent l'art pour servir les intérêts individuels. C'est même plus fondamentalement encore une réaction contre l'expulsion de l'œuvre et de l'art hors de la réalité du monde, comme on l'a vu; cette «révolte» a bien de ce point de vue un sens politique car c'est le sens, public et politique, de l'œuvre d'art de contribuer à la réalité du monde partagé par son simple apparaître, et d'être dans ce monde comme une chose dont la culture propre à cet "être-ensemble » des hommes puisse prendre soin pour la préserver.

L'autonomie de la sphère artistique, c'est aussi la reconnaissance de la différence de registre dans la vita activa. L'artiste fait une élaboration de matériaux : pierre, couleurs, sons, mots, etc., qui est une réification ; il agit en homo faber dans son atelier, non en homme d'action. Son œuvre prend place dans le monde public, mais l'homo faber n'est pas un homme public ou politique : il est seul avec son œuvre, dans une élaboration qui a un commencement défini et une fin déterminée, quand l'œuvre sort de l'atelier. L'homme d'action, quant à lui, n'est pas comme tel solitaire, il est d'emblée en interaction avec les autres et ne maîtrise pas le terme de son action.

Le rapport de l'œuvrer de l'artiste et de l'action de l'homme politique est en tension et il est complexe, comme le montre la deuxième partie de l'essai sur «La Crise de la culture». L'œuvre, une fois qu'elle devient publique, échappe à son producteur. Si elle est « autonome » par rapport aux autres produits de l'homo faber, par rapport aux objets d'usage, c'est qu'elle transcende la sphère des besoins et des fonctions propres à l'outil. Mais

${ }^{1}$ Ibid., p. 287.

${ }^{2}$ Ibid., p. 271.

${ }^{3}$ Cf. Hannah Arendt, La Crise de la culture, op. cit., p. 314. 
comme objet durable du monde, elle dépend d'une activité publique de préservation qui est à proprement parler la culture. C'est là son "autonomie » par rapport à la consommation et à l'usage. Mais ce thème de l'autonomie de la sphère artistique commande que l'on se tourne non pas seulement dès lors vers les positions de l'artiste et de l'œuvre mais aussi vers celle du spectateur. De ce point de vue, il faut relever les références au désintéressement de Kant.

Parlant des photographies où la figure humaine n'apparaît plus et qui, dit-il, commencent à « devenir des pièces à conviction pour le procès de l'histoire ${ }^{1}$, Benjamin souligne qu' « elles en appellent déjà à un regard déterminé ». "Elles ne se prêtent plus à une contemplation détachée. Elles inquiètent celui qui les regarde $»^{2}$. Dans l'analyse du cinéma, il fait, en toute bonne logique avec l'instrumentalité de l'œuvre, du spectateur d'abord un « expert» qui « fait passer un test» (la comparaison allant à une «épreuve d'aptitude professionnelle »), ou un «demi expert», pour finalement parler de ce public expert comme d'un « examinateur distrait» et ce, après avoir mis en contraste la distraction avec le recueillement: «Celui qui se recueille devant une œuvre d'art s'y abîme », tandis que « la masse distraite recueille l'œuvre d'art en elle $»^{3}$. En rapprochant la réception au cinéma, " distraite et collective », dont le modèle est tactile, c'est-à-dire pratique, de celle de l'architecture $^{4}$, Benjamin 1'oppose au modèle de la théorie esthétique traditionnelle qui privilégie la contemplation, un modèle visuel donc, dont le recueillement isolé renvoie à l'origine cultuelle une fois encore. La comparaison entre la peinture et le cinéma a fourni l'opposition des attitudes : si la toile « invite le spectateur à la contemplation » ${ }^{5}$ - dans laquelle il "peut s'abandonner à ses associations d'idées »-, l'image cinématographique, quant à elle, ne laisse le temps de rien de tel: c'est l'effet de choc qui l'emporte, empêchant toute "perte» du spectateur en contemplation. La contemplation recueillie individuelle est qualifiée de "comportement asocial ${ }^{6}$ et rapportée à une « bourgeoisie dégénérée ». L'expertise distraite et collective est rapportée à la masse des salles obscures. Du point de vue

${ }^{1}$ Walter Benjamin, «L'Euvre d'art à l'époque de sa reproductibilité technique », art. cit., p. 286.

${ }^{2}$ Idem. On pourrait analyser dans le passage en question les références à l'absence de liberté du spectateur : Benjamin parle de « directives » qui deviennent encore «plus impérieuses $»$ avec le cinéma.

${ }^{3}$ Ibid., p. 289-290 et note, p. 295, p. 313, p. 311.

${ }^{4}$ Ibid., p. 311.

${ }^{5}$ Ibid., p. 309.

${ }^{6}$ Ibid., p. 308. 
politique auquel il se place, le gros avantage de la réception du film par la masse serait que

plus que nulle part ailleurs, les réactions individuelles, dont l'ensemble constitue la réaction massive du public, prennent en compte, dès le départ, leur transformation imminente en un phénomène de masse et que, au moment même où elles se manifestent, ces réactions se contrôlent mutuellement ${ }^{1}$.

Indépendamment même de ce que peut donner à craindre cette sorte d'autocensure préventive d'un contrôle de la masse par la masse, le lecteur d'Arendt voit l'abîme se creuser entre cette analyse et l'usage qu'Arendt fera du modèle kantien du jugement désintéressé. Ce que fournit le texte de Kant à ses yeux, c'est le modèle d'un regard, d'un jugement, libéré pour le monde parce que libéré des soucis quant aux nécessités vitales et aux considérations utilitaires. Libéré pour le monde veut dire attentif, et actif chez Kant, attentif à l'objet pour lui-même, pour ce qu'il donne à voir, tel qu'il est pour le monde, et non par rapport à tel ou tel usager; mais cela veut dire aussi attentif au point de vue d'autrui : la liberté du jugement individuel est celle d'un jugement en phase avec le caractère partagé du monde, et ce jugement est précisément celui qui peut prendre en souci les objets du monde, et parce que ce monde est un monde partagé, cela veut dire une prise de soin commune, active, des choses du monde, ce qui exige la tenue en compte du point de vue de tout autre qui partage ce monde. Il s'agit, dit Arendt, de courtiser l'accord d'autrui à son propre jugement, de faire preuve de cette «mentalité élargie» qu'évoque $\mathrm{Kant}^{2}$. La validité spécifique du jugement réfléchissant kantien est là, dans cette « communication anticipée avec autrui avec qui je sais finalement devoir trouver un accord ${ }^{3}$ et dans cette recherche d'un jugement qui soit valide " pour toute personne singulière qui juge ${ }^{4}$, ce qui veut dire que ce jugement «n'est pas valide pour qui ne juge pas, ni pour ceux qui ne sont pas membres du domaine public où les objets du jugement apparaissent $»^{5}$.

Aux yeux d'Arendt, il n'est pas douteux que ce jugement désintéressé est politique au sens fort: il concerne d'emblée et de droit l'«êtreensemble » des hommes, leur manière de partager leur monde commun ; il n'est pas douteux non plus qu'en réduisant le désintéressement à un re-

${ }^{1}$ Ibid., p. 301.

${ }^{2}$ Hannah Arendt, La Crise de la culture, op. cit., p. 281.

${ }^{3}$ Idem.

${ }^{4}$ Ibid., p. 282 citant Kant.

${ }^{5}$ Ibid., p. 282. 
cueillement solitaire et antisocial, Benjamin méconnaît ce qui est le plus important d'un point de vue politique; il n'est pas douteux enfin qu'en collectivisant comme il le fait la réception par la masse, Benjamin commet l'erreur politique majeure non pas seulement de négliger la pluralité des hommes, leur différence individuelle dans leur égalité de droits, mais de la nier au profit d'une illusion de sujet collectif : cette masse qui n'est rien qu'une somme d'intérêts individuels, rien qu'une foule dont on pourra se disputer le « contrôle » ou obtenir l'autocensure, la neutralisation de la foule par la foule ; et qui représente assurément l'anéantissement de tout jugement individuel libre et soucieux de convaincre des égaux. Sans compter que si jugement il y a au sein de cette foule, c'est en vertu des critères de la consommation : fraîcheur et nouveauté et non eu égard au « vivre-ensemble ». 